\title{
Association between the level of education and knowledge, attitudes and practices regarding dengue in the Caribbean region of Colombia
}

Fredi Alexander Diaz-Quijano ${ }^{1 *}$, Ruth Aralí Martínez-Vega², Alfonso J. Rodriguez-Morales ${ }^{2,3}$, Ronald Alexander Rojas-Calero², María Lucrecia Luna-González² and Ronald Giovanny Díaz-Quijano²

\begin{abstract}
Background: Community integration in dengue control requires assessments of knowledge, attitudes and practices (KAPs), which can vary widely according to demographic and educational factors. We aimed to describe and compare the KAPs according to level of education in municipalities in the Caribbean region of Colombia.

Methods: A survey was administered from October to December 2015, including families selected through probabilistic sampling in eleven municipalities. The analysis focused on the comparative description of the responses according to level of education. The KAP prevalence ratios (PR) according to education were estimated using Poisson regression (robust), including age and sex as adjustment variables.

Results: Out of 1057 participants, 1054 (99.7\%) surveys were available for analysis, including 614 (58.3\%) who had a high school level of education or higher and 440 (41.7\%) who had a lower level of education (not high school graduates). The high school graduates showed a higher frequency of correct answers in relation to knowledge about dengue symptoms and transmission.

On the other hand, graduates showed a higher probability of practices and attitudes that favor dengue control, including not storing water in containers (PR: 2.2; 95\% Confidence Interval [CI]: 1.42-3.43), attend community meetings (PR: 1.33; 95\% Cl: 1.07-1.65), educate family members and neighbors in prevention measures (PR: 1.35; 95\% Cl: 1.15-1.59).

Conclusions: Level of education could be a key determinant of knowledge of the disease and its transmission, as well as attitudes and practices, especially those that involve the integration of community efforts for dengue control.
\end{abstract}

Keywords: Dengue, Knowledge, Attitudes, Practices, Education, Colombia

\section{Background}

Dengue fever is the viral illness transmitted by arthropods with the highest incidence in the world and is a growing cause of mortality in the countries of Latin America and the Caribbean [1, 2]. In 2016, Colombia was the Latin American country with the highest dengue

\footnotetext{
*Correspondence: frediazq@msn.com

'Departamento de Epidemiologia, Faculdade de Saúde Pública, Universidade de São Paulo, São Paulo, Brazil

Full list of author information is available at the end of the article
}

mortality rate (4 deaths per million inhabitants), contributing 199 of the 1032 cases of the continent [1].

Community participation in the activities for the control and early recognition of the disease is essential to reduce the burden associated with the incidence and mortality from dengue fever [3]. Therefore, community integration requires assessments of knowledge, attitudes and practices (KAPs). However, KAPs regarding dengue vary widely among endemic regions and countries [4-9]. This can condition the ability of a community to identify, treat and control these emerging and re-emerging diseases. 
The Caribbean region of Colombia has shown a rising trend in the incidence of dengue over the last decade. In particular, over the last decade, the department of La Guajira has exceeded the national average, reaching an incidence higher than 200 cases per 100,000 inhabitants in 2013 [10]. This has made it particularly necessary to establish prevention and control measures involving the community in this region. Despite all of this, little is known about the KAPs regarding dengue in this region, which are of great importance in this context.

In addition to the above, it is essential to recognize the determinants of the KAPs in order to guide control strategies [11]. In this sense, level of education could be an essential factor for both the acquisition of knowledge, as well as the implementation of preventive measures. Therefore, the objective of this study is to describe the KAPs in municipalities of the Caribbean region of Colombia and to establish their association with participants' level of education.

\section{Methods}

This paper is part of a population-based cohort study [10]. A survey was administered from October to December 2015, including families selected through probabilistic sampling by conglomerates in municipalities of 3 departments in Colombia: La Guajira, Cesar and Magdalena (Fig. 1). One adult from each family was interviewed by administering a structured questionnaire on KAPs regarding dengue. The form was based on one previously used by Cáceres et al. in another Colombian population [7].

Most of the surveys were administered in the Department of La Guajira (88\%), which is located in the northern region of Colombia in which approximately $45 \%$ of the population is self-recognized as indigenous and nearly $15 \%$ as Afro-descendant. According to the census conducted in 2005, 32.1\% of the population living in La Guajira has no education and $27.6 \%$ has only reached the basic primary level [12].

For this study, a sample was planned of at least 1000 families selected in 11 municipalities in the Colombian Caribbean (Fig. 1). The municipalities included nine in the department of La Guajira (Riohacha, Albania, Fonseca, San Juan del Cesar, Distracción, Maicao, Villanueva, Uribia and Manaure) which cover $87.2 \%$ of the population of this department [13]. Moreover, it included one municipality in Cesar (Valledupar) and another in Magdalena (El Retén).

The overall population living in the eleven municipalities was estimated at approximately 1.3 million inhabitants [13]. All of these municipalities were considered endemic for dengue, including three that were classified by the Ministry of Health and Social Protection as hyperendemic (Riohacha, Villanueva and Valledupar), seven as meso-endemic and one considered hypoendemic (El
Retén) [14]. The number of homes per municipality was assigned considering the size of the population (Fig. 1), ranging from 22 families in El Retén (Magdalena) to 205 in Riohacha (La Guajira). Sampling by conglomerates was carried out for the selection of participants. Thus, blocks were randomly selected in each municipality and on each block, following a mapping and population analysis, a number of homes was randomly selected. The number of blocks selected per municipality was calculated in order to require the inclusion of between five and seven houses per block to reach the number of families assigned to the corresponding municipality. In each of the homes, residents were invited to participate and the questionnaire of this study was administered to the responsible adult who was at home at the time of the visit. When a family did not consent to participate, another house on the same block was randomly selected [10].

Interviews were applied by previously trained professional nurses, who carried out the informed consent process and the interview using a standardized questionnaire. This questionnaire included questions about KAPs regarding dengue disease and vector control. Each of the forms was typed in duplicate and the copies were compared. Typing inconsistencies were resolved by reviewing the original form.

\section{Statistical analysis}

The analysis focused on the comparative description of the responses according to level of education. To this end, respondents who completed high school studies were compared to those with lower levels of education. For these comparisons, the Chi square test was used for categorical variables and the Mann-Whitney test was used for quantitative variables.

The associations identified between level of education and each of the responses regarding KAPs, were evaluated in a multiple model including age and sex as adjustment variables. This was done to estimate the prevalence ratio (PR) using the robust Poisson regression model for calculating the $95 \%$ confidence intervals (95\% CI) [15]. Statistical significance was defined as a $p$ value $<0.05$ (two-tailed). The STATA v11.0 program was used for the statistical analysis.

\section{Results}

A total of 1057 surveys was obtained, distributed in the 11 municipalities (Fig. 1), one of the surveys from the city of Manaure was excluded because it did not include data on age. In addition, two participants did not provide information on their level of education. 614 of the 1054 remaining respondents had a high school level of education or higher and 440 had a lower level of education (not high school graduates).

Most of the participants were female (81.3\%) and the median age was 42 years (Table 1). Although the 


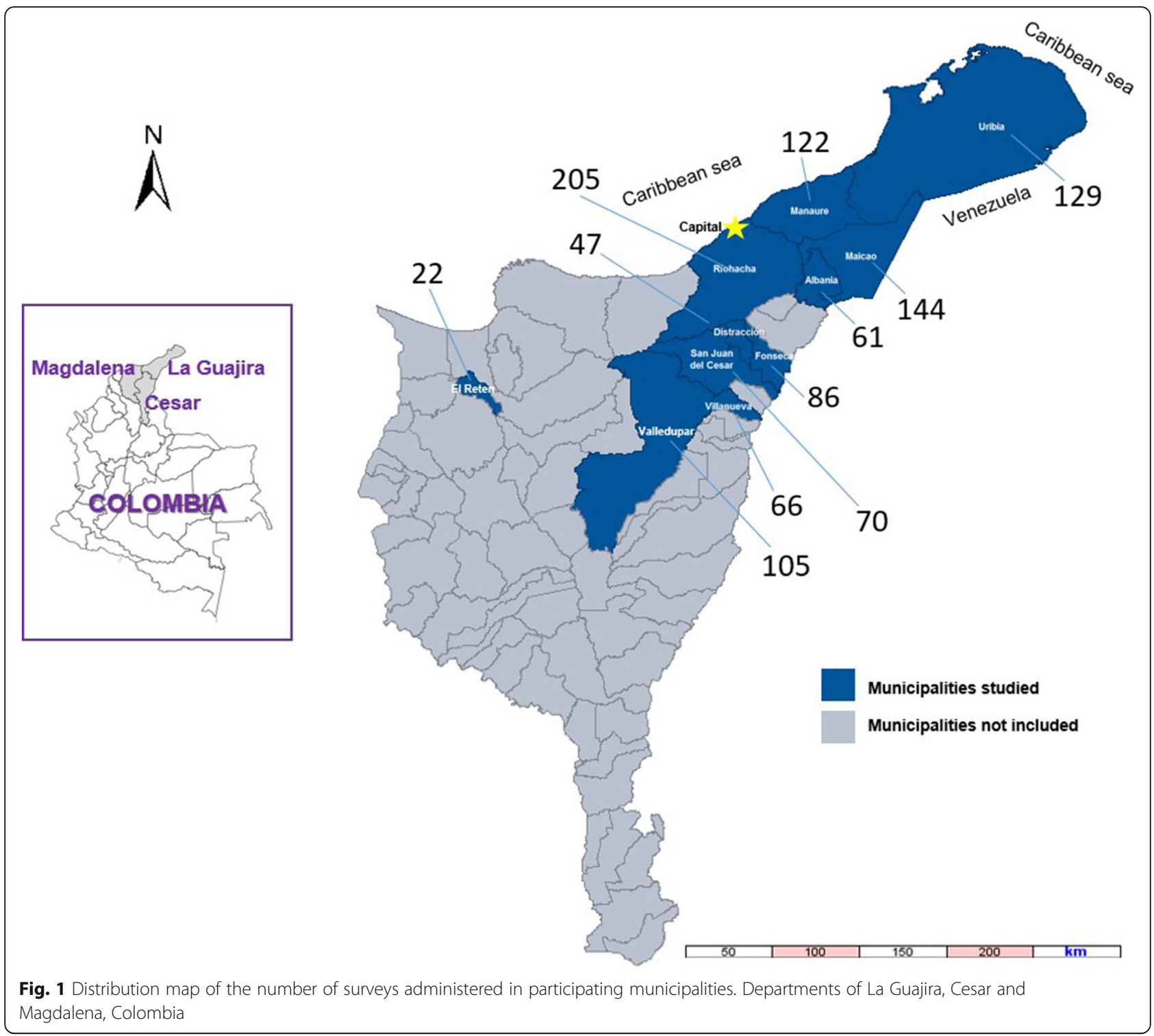

distribution by sex was not different in relation to the level of education, participants who were high school graduates were significantly younger compared to those who were not high school graduates (median age 37 years vs. 51 years, respectively $[p<0.001])$. In relation to the disease, high school graduates more often recognized fever (98.4\% vs $93.4 \%, \mathrm{p}<0.001)$, aches and pains $(36.5 \%$ vs 29.2, $p=0.01$ ) and petechiae (red dots on the skin: $13.4 \%$ vs $7.7 \%, p=0.004$ ) as signs of dengue. All other manifestations evaluated were recognized with similar frequency in the comparison groups (Table 1).

In relation to behavior, most respondents indicated that they would turn to a health institution or doctor when a family member had an illness compatible with dengue. In addition, 28 respondents stated that they had a family member, who lived in the same house, who got dengue in the last month. These responses on the behavior and the frequency of illness in the family had a similar frequency between high school graduates and non-graduates $(p \geq 0.50$; Table 1$)$.

In relation to knowledge about transmission, $87.4 \%$ of respondents knew how the disease was transmitted, 25.4\% knew the name of the mosquito and $37.6 \%$ knew what the mosquito looked like. This knowledge was significantly more frequent in high school graduates compared with those with lower levels of education $(p<0.001$; Table 1$)$. In turn, high school graduates more frequently stated that the mosquito could reproduce in clean water compared to non-high school graduates ( $45 \%$ vs. $36.9 \%, p=0.01)$. However, high school graduates less frequently stated that the mosquito could reproduce in rain water $(4.1 \%$ vs $7.3 \%, p=$ $0.02)$. The latter was the only correct response on which the high school graduates had a significantly lower frequency than non-high school graduates (Table 1). 
Table 1 Knowledge and practices in relation to the dengue disease and knowledge of its transmission according to level of education

\begin{tabular}{|c|c|c|c|c|}
\hline Dependent variables & Total & High school graduates & Non-high school graduates & $P$ value* \\
\hline Female sex - No (\%) & $857 / 1054(81.3 \%)$ & $497 / 614(80.9 \%)$ & $360 / 440(81.8 \%)$ & 0.72 \\
\hline Age - Median (RIC) & $42(32-55)$ & $37(29-48)$ & $51(38-62)$ & $<0.001$ \\
\hline \multicolumn{5}{|l|}{ Symptoms recognized as signs of dengue: } \\
\hline Fever & 1014/1053 (96.3\%) & $604 / 614(98.4 \%)$ & $410 / 439(93.4 \%)$ & $<0.001$ \\
\hline Aches and pains & $352 / 1053(33.4 \%)$ & $224 / 614(36.5 \%)$ & $128 / 439(29.2 \%)$ & 0.01 \\
\hline Headache & $474 / 1053(45 \%)$ & $277 / 614(45.1 \%)$ & 197/439 (44.9\%) & 0.94 \\
\hline Bone pain & $282 / 1053(26.8 \%)$ & $168 / 614(27.4 \%)$ & $114 / 439(26 \%)$ & 0.61 \\
\hline Pain in the eyes & $71 / 1053(6.7 \%)$ & $40 / 614(6.5 \%)$ & $31 / 439(7.1 \%)$ & 0.73 \\
\hline Sweating & $51 / 1053(4.8 \%)$ & $33 / 614(5.4 \%)$ & 18/439 (4.1\%) & 0.34 \\
\hline Vomiting & $471 / 1053(44.7 \%)$ & 283/614 (46.1\%) & $188 / 439(42.8 \%)$ & 0.29 \\
\hline Diarrhea & 412/1053 (39.1\%) & 232/614 (37.8\%) & 180/439 (41\%) & 0.29 \\
\hline Stomach ache & $79 / 1053(7.5 \%)$ & $43 / 614(7 \%)$ & $36 / 439(8.2 \%)$ & 0.47 \\
\hline Rash & $94 / 1053(8.9 \%)$ & $61 / 614(9.9 \%)$ & $33 / 439(7.5 \%)$ & 0.17 \\
\hline Red spots on the skin & 116/1053 (11\%) & $82 / 614(13.4 \%)$ & $34 / 439(7.7 \%)$ & 0.004 \\
\hline Bleeding gums & 127/1053 (12.1\%) & $80 / 614(13 \%)$ & $47 / 439(10.7 \%)$ & 0.25 \\
\hline Nosebleed & 138/1053 (13.1\%) & $88 / 614(14.3 \%)$ & $50 / 439(11.4 \%)$ & 0.16 \\
\hline \multicolumn{5}{|l|}{$\begin{array}{l}\text { Conduct when a family } \\
\text { member has dengue: }\end{array}$} \\
\hline Care at home & 26/1053 (2.5\%) & $15 / 614(2.4 \%)$ & $11 / 439(2.5 \%)$ & 0.95 \\
\hline Go to the doctor & $553 / 1053(52.5 \%)$ & $317 / 614(51.6 \%)$ & 236/439 (53.8\%) & 0.49 \\
\hline Go to a health institution & 29/1053 (2.8\%) & $310 / 614(50.5 \%)$ & $231 / 439(52.6 \%)$ & 0.50 \\
\hline Go to a pharmacy & 1/1053 (0.1\%) & $0 / 614(0 \%)$ & $1 / 439(0.2 \%)$ & 0.24 \\
\hline Self-medicate & 28/1053 (2.7\%) & $18 / 614(2.9 \%)$ & $10 / 439(2.3 \%)$ & 0.52 \\
\hline $\begin{array}{l}\text { In the last month, someone } \\
\text { in this family, living at home, at dengue: }\end{array}$ & 28/1048 (2.7\%) & $17 / 610(2.8 \%)$ & $11 / 438(2.5 \%)$ & 0.79 \\
\hline \multicolumn{5}{|l|}{ Knowledge regarding transmission: } \\
\hline Knows how dengue is transmitted & 918/1051 (87.3\%) & $571 / 613(93.1 \%)$ & $347 / 438(79.2 \%)$ & $<0.001$ \\
\hline Knows the name of the mosquito & 266/1051 (25.3\%) & 202/613 (33\%) & $64 / 438(14.6 \%)$ & $<0.001$ \\
\hline Knows what the mosquito looks like & $395 / 1052(37.5 \%)$ & $266 / 614(43.3 \%)$ & $129 / 438(29.5 \%)$ & $<0.001$ \\
\hline Recognizes mosquito larvae & $853 / 1050(81.2 \%)$ & $504 / 614(82.1 \%)$ & $349 / 436(80 \%)$ & 0.40 \\
\hline \multicolumn{5}{|l|}{$\begin{array}{l}\text { Means where the mosquito is } \\
\text { believed to reproduce }\end{array}$} \\
\hline Stagnant water & $518 / 1052(49.2 \%)$ & $302 / 613(49.3 \%)$ & $216 / 439(49.2 \%)$ & 0.98 \\
\hline Clean water & $438 / 1052(41.6 \%)$ & 276/613 (45\%) & $162 / 439(36.9 \%)$ & 0.01 \\
\hline Rainwater & $57 / 1052(5.4 \%)$ & 25/613 (4.1\%) & $32 / 439(7.3 \%)$ & 0.02 \\
\hline Dirty water & 194/1052 (18.4\%) & 104/613 (17\%) & $90 / 439(20.5 \%)$ & 0.14 \\
\hline Drain water & 41/1052 (3.9\%) & 19/613 (3.1\%) & $22 / 439(5 \%)$ & 0.11 \\
\hline
\end{tabular}

${ }^{*} p$-value was obtained by using the Chi square test for categorical variables. For the age variable, the $p$-value was obtained using the Mann-Whitney test

In relation to the availability of potential breeding sites, high school graduates more often mentioned tanks and sinks compared to non-high school graduates (Table 2). However, when asked about other containers, the high school graduates most frequently responded that they had no other container compared to non-high school graduates $(11.7 \%$ vs. $6.8 \%$, respectively, $p=0.01)$. It was interesting that most respondents with a sink (67.8\%) wash it less than once per week. However, no differences were observed between high school graduates and nongraduates, in relation to the practices to prevent mosquitoes from breeding in these containers (Table 2).

In relation to family and community attitudes and practices, high school graduates attend meetings (31.3\% 
Table 2 Availability of breeding sites and methods used to prevent mosquito reproduction

\begin{tabular}{|c|c|c|c|c|}
\hline Dependent variables & Total & High school graduates & Non-high school graduates & $p$ value \\
\hline Do you have a tank for water? & $186 / 1049(17.7 \%)$ & $126 / 613(20.6 \%)$ & $60 / 436(13.8 \%)$ & 0.01 \\
\hline \multicolumn{5}{|c|}{ Methods used to prevent mosquito breeding in the tank: } \\
\hline Covers the tank & 16/184 (8.7\%) & $12 / 125(9.6 \%)$ & $4 / 59(6.8 \%)$ & 0.53 \\
\hline Washes the tank & 128/184 (69.6\%) & $86 / 125(68.8 \%)$ & $42 / 59(71.2 \%)$ & 0.74 \\
\hline Using temephos (Abate ${ }^{\oplus}$ ) & 14/184 (7.6\%) & $12 / 125(9.6 \%)$ & $2 / 59(3.4 \%)$ & 0.14 \\
\hline Uses bleach & $11 / 184(6 \%)$ & $7 / 125(5.6 \%)$ & $4 / 59(6.8 \%)$ & 0.75 \\
\hline Other means & 8/184 (4.3\%) & $8 / 125(6.4 \%)$ & $0 / 59(0 \%)$ & 0.05 \\
\hline None & $26 / 184(14.1 \%)$ & $16 / 125(12.8 \%)$ & 10/59 (16.9\%) & 0.45 \\
\hline \multicolumn{5}{|l|}{ How do you wash the tank?: } \\
\hline Just water & 6/182 (3.3\%) & $3 / 122(2.5 \%)$ & $3 / 60(5 \%)$ & 0.37 \\
\hline Water and a brush & $22 / 182(12.1 \%)$ & 16/122 (13.1\%) & $6 / 60(10 \%)$ & 0.54 \\
\hline With detergent & 24/182 (13.2\%) & $14 / 122(11.5 \%)$ & $10 / 60(16.7 \%)$ & 0.33 \\
\hline With detergent and a brush & 135/182 (74.2\%) & $92 / 122(75.4 \%)$ & $43 / 60(71.7 \%)$ & 0.59 \\
\hline With others & 10/182 (5.5\%) & $8 / 122(6.6 \%)$ & $2 / 60(3.3 \%)$ & 0.37 \\
\hline Washes the tank less than once per week & 40/182 (22\%) & $26 / 122(21.3 \%)$ & $14 / 60(23.3 \%)$ & 0.76 \\
\hline Has a sink to store water & $567 / 1052(53.9 \%)$ & $358 / 614(58.3 \%)$ & 209/438 (47.7\%) & $<0.001$ \\
\hline \multicolumn{5}{|c|}{ Methods used to prevent mosquito breeding in the sink: } \\
\hline Covers the sink & $309 / 566(54.6 \%)$ & 195/357 (54.6\%) & $114 / 209(54.5 \%)$ & 0.99 \\
\hline Washes the sink & $329 / 566(58.1 \%)$ & 204/357 (57.1\%) & $125 / 209(59.8 \%)$ & 0.54 \\
\hline Using temephos (Abate ${ }^{\oplus}$ ) & $37 / 566(6.5 \%)$ & 25/357 (7\%) & $12 / 209(5.7 \%)$ & 0.56 \\
\hline Uses bleach & $46 / 566(8.1 \%)$ & $27 / 357(7.6 \%)$ & 19/209 (9.1\%) & 0.52 \\
\hline Other means & 15/566 (2.7\%) & $8 / 357(2.2 \%)$ & $7 / 209$ (3.3\%) & 0.43 \\
\hline None & $35 / 566(6.2 \%)$ & $23 / 357(6.4 \%)$ & $12 / 209$ (5.7\%) & 0.74 \\
\hline \multicolumn{5}{|l|}{ How do you wash the sink?: } \\
\hline Just water & 13/563 (2.3\%) & $8 / 356(2.2 \%)$ & $5 / 207(2.4 \%)$ & 0.90 \\
\hline Water and a brush & $81 / 563(14.4 \%)$ & $48 / 356(13.5 \%)$ & $33 / 207$ (15.9\%) & 0.42 \\
\hline With detergent & $51 / 563(9.1 \%)$ & $34 / 356(9.6 \%)$ & 17/207 (8.2\%) & 0.59 \\
\hline With detergent and a brush & $452 / 563(80.3 \%)$ & $282 / 356(79.2 \%)$ & 170/207 (82.1\%) & 0.40 \\
\hline With others & $54 / 563(9.6 \%)$ & $39 / 356(11 \%)$ & 15/207 (7.2\%) & 0.15 \\
\hline Washes the sink less than once per week & $376 / 555(67.7 \%)$ & $234 / 350(66.9 \%)$ & $142 / 205(69.3 \%)$ & 0.56 \\
\hline \multicolumn{5}{|l|}{ Other containers store water: } \\
\hline Cans & 182/1052 (17.3\%) & $107 / 614(17.4 \%)$ & $75 / 438(17.1 \%)$ & 0.90 \\
\hline Buckets & $429 / 1052(40.8 \%)$ & 238/614 (38.8\%) & 191/438 (43.6\%) & 0.11 \\
\hline Jerrycan & $92 / 1052(8.7 \%)$ & $48 / 614(7.8 \%)$ & $44 / 438(10 \%)$ & 0.21 \\
\hline Bottles & 6/1052 (0.6\%) & $3 / 614(0.5 \%)$ & $3 / 438(0.7 \%)$ & 0.68 \\
\hline Pots & 14/1052 (1.3\%) & $7 / 614(1.1 \%)$ & $7 / 438(1.6 \%)$ & 0.52 \\
\hline Other container & $388 / 1052(36.9 \%)$ & 228/614 (37.1\%) & $160 / 438(36.5 \%)$ & 0.84 \\
\hline None - other & 102/1052 (9.7\%) & $72 / 614(11.7 \%)$ & $30 / 438(6.8 \%)$ & 0.01 \\
\hline
\end{tabular}

vs. $24.9 \%, p=0.02$ ) and stated that they educate members of their family and neighbors regarding measures to prevent dengue fever $(46.6 \%$ vs. $37 \%, p=0.002)$, more often than non-high school graduates (Table 3). In addition, high school graduates more often stated that they can carry out actions to control dengue (29.6\% vs.
21.9\%, $p=0.01)$ and that their suggestions to control dengue are heard ( $42 \%$ vs. $33.5 \%, p=0.01)$. In relation to the difficulties involved in carrying out preventive measures against dengue, the high school graduates more often mentioned the lack of time (30.9\% vs. $21.9 \%, p=$ $0.001)$ and, less often, the lack of resources $(16.8 \%$ vs. 
Table 3 Community attitudes and practices for dengue control

\begin{tabular}{|c|c|c|c|c|}
\hline Dependent variables & Total & High school graduates & $\begin{array}{l}\text { Non-high } \\
\text { school graduates }\end{array}$ & $p$ value \\
\hline Attends community meetings & $301 / 1052(28.6 \%)$ & 192/614 (31.3\%) & $109 / 438(24.9 \%)$ & 0.02 \\
\hline Participates in activities to prevent dengue in the neighborhood & 200/1051 (19\%) & $124 / 613(20.2 \%)$ & $76 / 438(17.4 \%)$ & 0.24 \\
\hline Agrees with neighbors to collect garbage around the home & $235 / 1052(22.3 \%)$ & $144 / 614(23.5 \%)$ & $91 / 438(20.8 \%)$ & 0.30 \\
\hline $\begin{array}{l}\text { Do you educate other family members and/or neighbors } \\
\text { regarding measures to prevent dengue? }\end{array}$ & $447 / 1050(42.6 \%)$ & $285 / 612(46.6 \%)$ & $162 / 438(37 \%)$ & 0.002 \\
\hline Do you have the ability to take action to control dengue? & $278 / 1052(26.4 \%)$ & $182 / 614(29.6 \%)$ & $96 / 438(21.9 \%)$ & 0.01 \\
\hline Do you consider your suggestions to control dengue are heard? & $404 / 1051(38.4 \%)$ & $257 / 612(42 \%)$ & $147 / 439(33.5 \%)$ & 0.01 \\
\hline Do you lead campaigns to prevent dengue? & $87 / 1052(8.3 \%)$ & $53 / 613(8.6 \%)$ & $34 / 439(7.7 \%)$ & 0.60 \\
\hline Do you get help for dengue prevention programs? & $99 / 1048(9.4 \%)$ & $65 / 610(10.7 \%)$ & $34 / 438(7.8 \%)$ & 0.11 \\
\hline $\begin{array}{l}\text { Do you file claims with the authorities when you consider } \\
\text { they are not taking actions for dengue control in your community? }\end{array}$ & $246 / 1049(23.5 \%)$ & $152 / 613(24.8 \%)$ & $94 / 436(21.6 \%)$ & 0.22 \\
\hline \multicolumn{5}{|l|}{$\begin{array}{l}\text { Reasons that hinder the implementation of preventive } \\
\text { measures against dengue: }\end{array}$} \\
\hline Lack of time & $286 / 1053(27.2 \%)$ & 190/614 (30.9\%) & $96 / 439(21.9 \%)$ & 0.001 \\
\hline Lack of information & $592 / 1053(56.2 \%)$ & $349 / 614(56.8 \%)$ & $243 / 439(55.4 \%)$ & 0.63 \\
\hline Lack of funds & 203/1053 (19.3\%) & 103/614 (16.8\%) & $100 / 439(22.8 \%)$ & 0.01 \\
\hline Other reason & $79 / 1053(7.5 \%)$ & $44 / 614(7.2 \%)$ & $35 / 439(8 \%)$ & 0.62 \\
\hline \multicolumn{5}{|l|}{$\begin{array}{l}\text { You consider that the party responsible for taking measures } \\
\text { to prevent dengue should be: }\end{array}$} \\
\hline The municipal government & $590 / 1053(56 \%)$ & $335 / 614(54.6 \%)$ & 255/439 (58.1\%) & 0.26 \\
\hline Medical staff & $62 / 1053(5.9 \%)$ & $37 / 614(6 \%)$ & $25 / 439(5.7 \%)$ & 0.82 \\
\hline Parents or guardians & $118 / 1053(11.2 \%)$ & $68 / 614(11.1 \%)$ & $50 / 439(11.4 \%)$ & 0.87 \\
\hline Everyone / All people living in the community & $490 / 1053(46.5 \%)$ & $297 / 614(48.4 \%)$ & 193/439 (44\%) & 0.16 \\
\hline Other & $82 / 1053(7.8 \%)$ & $48 / 614(7.8 \%)$ & $34 / 439(7.7 \%)$ & 0.97 \\
\hline
\end{tabular}

$22.8 \%, \mathrm{p}=0.01)$, compared to those with lower levels of education (Table 3 ).

In the multiple regression models, after adjusting for age and sex, the high school graduates showed a higher frequency of correct answers in relation to knowledge about dengue symptoms and transmission (Table 4). However, high school graduates less frequently responded that the mosquito could reproduce in rain water (PR: 0.51; 95\% CI: $0.3-0.88 ; p=0.02)$. We hypothesized that this association could be explained because sewerage problems in the region would lead to the recognition of rainwater by the community as dirty and inadequate for the development of Aedes spp.

On the other hand, graduates showed a higher probability of practices that favor dengue control, including not storing water in containers, attend community meetings and educating family members and neighbors regarding prevention measures (Table 4). In addition, high school graduates showed more positive attitudes toward dengue control, such as considering that they have the ability to perform actions of control and that are heard when they make suggestions. However, high school graduates also stated the lack of time as a difficulty in carrying out preventive measures.

Age, which was included in the models as an adjustment variable, was significantly associated with correct answers on dengue knowledge, including the recognition of the symptom of aches and pains, the name and appearance of the mosquito, and knowing that it reproduces in clean water. In addition, with increasing age of participants, there was a greater frequency of preventive practices and positive attitudes, such as not storing water in containers and educating relatives and neighbors, as well as feeling that they have the ability to take action and that their suggestions are heard.

Finally, regardless of the educational level and age, women were more likely to recognize certain signs of dengue, such as aches and pains (PR: 1.3; 95\% CI: $1.02-$ $1.65 ; p=0.03$ ) and petechiae (PR: $1.92 ; 95 \%$ CI: $1.07-$ $3.45 ; \mathrm{p}=0.03)$ and had a $26 \%$ greater probability of knowing that the mosquito reproduces in clean water (PR: $1.26 ; 95 \% \mathrm{CI}: 1.03-1.53 ; p=0.02$ ), compared to men (Table 4). 
Table 4 Knowledge, practices and attitudes regarding dengue in relation to level of education - Models adjusted by demographic variables*

\begin{tabular}{|c|c|c|c|}
\hline \multirow[t]{2}{*}{ Dependent variables } & \multicolumn{3}{|c|}{ Independent variables included in the models } \\
\hline & High school & Age (every 10 years) & Female sex (vs. male) \\
\hline \multicolumn{4}{|l|}{ Symptoms recognized as signs of dengue: } \\
\hline Fever & $1.06(1.03-1.09)$ & NS & NS \\
\hline Aches and pains & $1.37(1.14-1.66)$ & $1.09(1.02-1.16)$ & $1.3(1.02-1.65)$ \\
\hline Red spots on the skin & $1.55(1.03-2.33)$ & NS & $1.92(1.07-3.45)$ \\
\hline \multicolumn{4}{|l|}{ Knowledge regarding transmission: } \\
\hline Knows how dengue is transmitted & $1.17(1.11-1.24)$ & NS & NS \\
\hline Knows the name of the mosquito & $2.69(2.07-3.49)$ & $1.16(1.08-1.25)$ & NS \\
\hline Knows what the mosquito looks like & $1.66(1.39-1.99)$ & $1.11(1.05-1.17)$ & NS \\
\hline \multicolumn{4}{|l|}{ Means where the mosquito is believed to reproduce } \\
\hline Clean water & $1.44(1.23-1.7)$ & $1.15(1.1-1.21)$ & $1.26(1.03-1.53)$ \\
\hline Rainwater & $0.51(0.3-0.89)$ & NS & NS \\
\hline \multicolumn{4}{|l|}{ Practices regarding dengue } \\
\hline Does not store water in containers & $2.13(1.38-3.27)$ & $1.19(1.04-1.37)$ & NS \\
\hline Attends community meetings & $1.34(1.08-1.66)$ & NS & NS \\
\hline $\begin{array}{l}\text { Do you educate other family members } \\
\text { and/or neighbors regarding measures for prevention? }\end{array}$ & $1.37(1.17-1.6)$ & $1.09(1.04-1.14)$ & NS \\
\hline \multicolumn{4}{|l|}{ Attitudes regarding dengue control. } \\
\hline Do you have the ability to take action to control dengue? & $1.55(1.22-1.96)$ & $1.13(1.06-1.22)$ & NS \\
\hline Do you consider your suggestions to control dengue are heard? & $1.38(1.17-1.64)$ & $1.1(1.04-1.16)$ & NS \\
\hline $\begin{array}{l}\text { Do you consider that lack of time hinders } \\
\text { the implementation of preventive measures against dengue: }\end{array}$ & $1.39(1.11-1.74)$ & NS & NS \\
\hline
\end{tabular}

*For each of the dependent variables, a multiple regression model was obtained, including the variables of high school, age (as a continuous variable on the decade scale), and sex (female compared to male). This table only presents prevalence ratios and $95 \%$ confidence intervals of variables that were significant ( $p<$ 0.05). All these models were also adjusted by department (La Guajira vs others) NS: non-significant $(p>0.05)$

\section{Discussion}

This is a survey of important dimensions including more than 10 municipalities in the Caribbean region of Colombia. This, along with the probabilistic selection of participants would be strengths of this population survey. Based on these results, it can be inferred that almost the entire population studied recognizes dengue as a disease whose symptoms include fever. This suggests that this sign could be the potential motivation to turn to the health system in symptomatic cases. However, no other symptom is recognized by the majority of the population. In fact, each of the hemorrhagic manifestations was recognized as a sign of dengue in less than $15 \%$ of the respondents.

On the other hand, the majority of respondents stated that in order to care for dengue, they went to a doctor or a health institution. This suggests that this population recognizes dengue as a disease that requires medical attention. This could contrast with what has been observed in other populations that tend to selfmedicate, even with antibiotics before consulting due to a fever [16].
In relation to level of education, the symptoms of fever, aches and pains and "red spots on the skin" (which we interpreted as petechiae), were recognized more often by high school graduates compared to non-high school graduates. Fever and aches and pains are very frequent signs in patients with dengue $[17,18]$. In addition, skin manifestations, such as petechiae, can help us differentiate between dengue and other febrile diseases [19]. Therefore, it is plausible that people with a higher level of education would be better able to identify dengue and, therefore, seek professional help in time.

In turn, high school graduates had a higher frequency of correct responses to aspects related to transmission compared to non-high school graduates. This relationship between education and level of knowledge regarding dengue transmission and its control has already been observed in other studies [20,21]. However, it is interesting that, in spite of this, there were no significant differences in relation to the frequency of domestic practices to prevent mosquito breeding sites. Moreover, in the population studied, knowledge about the transmission of dengue was not positively associated with 
intra-domiciliary control practices (data not shown). This suggests that knowledge related to the reproduction of the mosquito does not ensure the practice of vector control methods in their homes. This is consistent with what has been observed in other populations, in which the frequency of good practices of vector control tends to be lower than the level of knowledge [22, 23].

However, level of education was associated with practices at the community level, such as attending meetings, educating other members of the family and/or neighbors. Moreover, high school graduates more frequently felt they had the ability to take actions of control and that their suggestions were heard. This suggests that level of education could be related to the degree of empowerment of the population to integrate and combine efforts to control transmission. These results are consistent with those observed in other studies in which the level of education was shown to be an independent predictor of attitudes and practices regarding dengue $[8,24]$.

As additional findings, this study shows that regardless of the level of education, age is directly associated with certain knowledge regarding the disease and mechanisms of transmission. This association is consistent with what has been observed in other studies [24]. In addition, with age, an increase has been observed in the frequency of positive attitudes and practices to control transmission.

Finally, regardless of age and level of education, women have a higher frequency of correct responses in relation to questions about knowledge regarding the disease and transmission. This could suggest that women may be more interested in or sensitive to acquiring skills that allow them to recognize the disease and prevent its transmission.

The limitations of this study include the difficulty of measuring how closely the answers about practices and attitudes, referred to by respondents, are related to those adopted in daily life. However, the results of this study provide evidence of how factors such as level of education and demographics (i.e. age and sex) could be determining factors of knowledge regarding the disease and its transmission, as well as attitudes and practices, especially those that involve the integration of community efforts to control the burden associated with dengue.

It is important to consider that the questionnaire was administered to the adult who was at home at the time of the visit, who were mostly women. This selection strategy could cause a selection bias that affects the representativeness of the survey. However, it is to be assumed that the person surveyed had a prominent role in the activities carried out at home. Therefore, we expected that the sample interviewed would adequately represent the control practices of those communities. In addition, after adjusting the demographic variables, we found that the associations were independent of variables such as sex and age.

On the other hand, compared to self-administered questionnaires, those administered by health personnel could promote socially desirable responses. The standardization of the questionnaire and the training of the interviewer could have minimized the risk of this information bias. On the other hand, if that bias occurred, it was probably not differential. Therefore, we believe that the associations found may persist regardless of the questionnaire administration strategy.

In Colombia, the health authorities lead the National Integrated Management Strategy for the Prevention and Control of Dengue that seeks to reduce morbidity and associated lethality. This strategy includes a component of social promotion, which comprises a regular program of permanent activities that includes the Communication for behavioral impact (COMBI) strategy [25]. However, one of the main challenges of this strategy is the continuity of community participation [26]. In order to guarantee the sustainability of these strategies, it is necessary the continuous monitoring of the community and the recognition of the behavior determinants.

In dengue, as well as for other tropical diseases, education is a fundamental pillar for integrated control, prevention and promotion. This determinant should be considered in the development of public policies that may be able to steadily reduce the disease and its impact on endemic regions. Specifically, the results of this study suggest that educational campaigns could focus on people with low educational levels, taking into account age groups. These targeted interventions could be more efficient and have a greater impact on preventive attitudes and practices.

\section{Conclusions}

Level of education could be a key determinant of knowledge of the disease and its transmission, as well as attitudes and practices, especially those that involve the integration of community efforts for dengue control. The results suggested that populations with a low educational level are especially vulnerable and their integration in control programs could be particularly difficult. Therefore, prioritizing these populations in programs aimed at controlling dengue and other arboviruses would be justified.

\section{Abbreviations \\ 95\% Cl: 95\% Confidence Interval; KAPs: Knowledge, attitudes and practices; PR: Prevalence Ratio}

\section{Acknowledgments}

The authors would like to thank Engineer, Diana Martinez Vega, for her invaluable support in administrative activities of the project; Dr. Yalil Bracho, for his participation in the logistics coordination; and the following professionals who assisted in the collection of the information: Dallys 
Almazo, Sorangel Brito, Greys C. Rios, Jacinta Arrieta, Heidist Bermúdez, Maripaz Vergara, Stephanie Arévalo, Yulibeth Gutierrez, Karen Kammerer, Maria A. Sierra, Milli Brito, Dainis Nieves, Johanna Perez, Rubys Oyola, Adriana Miranda, Jennifer Brito, Maria M. Kammerer, Eivis Morales.

\section{Ethical approval and consent to participate}

This study was evaluated and approved by the Research Ethics Committee of the Universidad de Santander - UDES, Bucaramanga, Santander, Colombia. All the participants signed an informed consent.

\section{Funding}

Project funded by the Department of La Guajira in an agreement with Organización Latinoamericana Para el Fomento de la Investigación en Salud [Latin American Organization for the Promotion of Research in Health] (OLFIS). Convention 019 / 2014.

\section{Availability of data and materials}

The possibility of sharing data and additional materials will be restricted by the provisions of Convention 019 / 2014. Currently, the raw data and additional materials used in this study are not available to other researchers. We do not have a predefined date to make the data available because this will be subject to the conclusion of the convention and the fulfillment of all the products compromised.

\section{Authors' contributions}

FADQ conceived the study, participated in its design and coordination, carried out the data analysis and prepared the first draft of the manuscript; RAMV participated in coordination and preparation of manuals and instruments for data collection and contributed to the discussion of the results; AJRM participated in the design of illustrations, including the Fig. 1, and assisted in drafting the manuscript; RARC participated in the administrative processes of the study and contributed to the discussion of the results; MLLG participated in the design of instruments to store information and data management; and RGDQ participated in project management and in the discussion of the results. All authors participated in the interpretation of data, carried out critical reviews of the manuscript, and read and approved the final manuscript. Thus, each author participated sufficiently in the work to take public responsibility for appropriate portions of the content and, therefore, agreed to be accountable for all aspects in ensuring that questions related to the accuracy or integrity of any part of the work are appropriately investigated and resolved.

\section{Competing interest}

No author has conflicts of interest related to this study.

\section{Consent for publication}

It is not applicable because the manuscript does not contain anyone's individual data.

\section{Publisher's Note}

Springer Nature remains neutral with regard to jurisdictional claims in published maps and institutional affiliations.

\section{Author details \\ 'Departamento de Epidemiologia, Faculdade de Saúde Pública, Universidade de São Paulo, São Paulo, Brazil. ${ }^{2}$ Organización Latinoamericana para el Fomento de la Investigación en Salud [Latin American Organization for the Promotion of Research in Health], Bucaramanga, Santander, Colombia. ${ }^{3}$ Public Health and Infection Research Group, Faculty of Health Sciences, Universidad Tecnológica de Pereira, Pereira, Risaralda, Colombia.}

\section{Received: 13 April 2017 Accepted: 10 January 2018}

\section{Published online: 16 January 2018}

\section{References}

1. PAHO. Dengue |Annual Cases Reported of Dengue | PAHO/WHO Data, Maps and Statistics [Internet]. 2017 [cited 2017 May 12]. Available from: http://www.paho.org/hq/index.php?option=com_topics\&view=rdmore\&cid= 6290\&ltemid $=40734$
2. Díaz-Quijano FA, Waldman EA. Factors associated with dengue mortality in Latin America and the Caribbean, 1995-2009: an ecological study. Am J Trop Med Hyg. 2012;86(2):328-34

3. Tran Tan T, Nguyen Thi Ngoc A, Nguyen Thanh H, Nguyen Trong L, Le Th C, Nguyen Phuoc C, et al. The impact of health education on mother's knowledge, attitude and practice (KAP) of dengue haemorrhagic fever. Dengue Bull. 2003;27:174-80.

4. Mayxay M, Cui W, Thammavong S, Khensakhou K, Vongxay V, Inthasoum L, et al. Dengue in peri-urban Pak-Ngum district, Vientiane capital of Laos: a community survey on knowledge, attitudes and practices. BMC Public Health [Internet]. 2013;13:434. Available from: https://www.ncbi.nlm.nih.gov/pmc/articles/PMC3645963/?tool=pmcentrez

5. Tung T-H, Huang H-L, Ho C-K, Chen C-D, Chan T-C, Li T, et al. The knowledge, attitude, and practice on dengue in Kaohsiung. Int J Infect Dis. 2012;16:2-157.

6. CJM K, Tuiten W, Sithiprasasna R, Kijchalao U, Jones JW, Scott TW. Dengue Knowledge and practices and their impact on Aedes Aegypti populations in Kamphaeng Phet, Thailand. Am J Trop Med Hyg. 2006; 74(4):692-700.

7. Caceres-Manrique Fde M, Vesga-Gomez C, Perea-Florez X, Ruitort M, Talbot $Y$. [Knowledge, attitudes and practice regarding dengue in two neighborhoods in Bucaramanga, Colombia]. Rev Salud. Publica. 2009;11: 27-38.

8. Dhimal M, Aryal KK, Dhimal ML, Gautam I, Singh SP, Bhusal CL, et al. Knowledge, attitude and practice regarding dengue fever among the healthy population of highland and lowland communities in Central Nepal. PLoS One. 2014;9(7)

9. Jeelani S, Sabesan S, Subramanian S. Community knowledge, awareness and preventive practices regarding denque fever in Puducherry e South India. Public Health [Internet]. 2015 [cited 2017 Mar 6];129:790-6. Available from: https://doi.org/10.1016/j.puhe.2015.02.026

10. Martínez-Vega RA, Rodriguez-Morales AJ, Bracho-Churio YT, Castro-Salas ME, Galvis-Ovallos F, Díaz-Quijano RG, et al. A prospective cohort study to assess seroprevalence, incidence, knowledge, attitudes and practices, willingness to pay for vaccine and related risk factors in dengue in a high incidence setting. BMC Infect Dis. 2016;16(1)

11. Frank AL, Beales ER, de Wildt G, Meza Sanchez G, Jones LL. "We need people to collaborate together against this disease": A qualitative exploration of perceptions of dengue fever control in caregivers' of children under 5 years, in the Peruvian Amazon. Paz-Soldan VA, editor. PLoS Negl Trop Dis [Internet]. 2017 Sep 5 [cited 2017 Nov 14];11(9):e0005755. Available from: http://dx.plos.org/https://doi.org/10.1371/journal.pntd.0005755

12. DANE. Boletín. Censo General 2005. Perfil La Guajira. [Internet]. 2010 [cited 2017 Mar 6]. Available from: http://www.dane.gov.co/files/censo2005/ PERFIL_PDF_CG2005/44000T7T000.PDF

13. DANE. Proyecciones de población [Internet]. [cited 2017 May 4]. Available from: https://www.dane.gov.co/index.php/estadisticas-por-tema/demografiay-poblacion/proyecciones-de-poblacion

14. Ministerio de Salud y Protección Social. República de Colombia. Patrón de Endemicidad para Dengue 2008-2013 [Internet]. [cited 2017 Nov 8]. Available from: https://www.minsalud.gov.co/Documentos\%20y \%20Publicaciones/MAPA\%20PATRON\%20DE\%20ENDEMICIDAD\%20DE \%20DENGUE\%20POR\%20MUNICIPIO pdf.

15. Barros AJD, Hirakata VN. Alternatives for logistic regression in cross-sectional studies: an empirical comparison of models that directly estimate the prevalence ratio. BMC Med Res Methodol [Internet]. 2003;3:21. Available from: http://www.pubmedcentral.nih.gov/articlerender.fcgi?artid= 521200\&tool=pmcentrez\&rendertype=abstract, https://www.ncbi.nlm.nih. gov/pmc/articles/PMC521200/?tool=pmcentrez.

16. Phuong HL, de Vries PJ, Nagelkerke N, Giao PT, Hung LQ, Binh TQ, et al. Acute undifferentiated fever in Binh Thuan province, Vietnam: imprecise clinical diagnosis and irrational pharmaco-therapy. Trop Med Int Health [Internet]. 2006 Jun [cited 2017 Mar 5];11(6):869-79. Available from: http:// doi.wiley.com/https://doi.org/10.1111/j.1365-3156.2006.01636.x

17. Díaz FA, Martínez RA, Villar LA. Clinical criteria to diagnose dengue in its early stages | Criterios clínicos para diagnosticar el dengue en los primeros días de enfermedad. Biomedica. 2006;26(1):22-30.

18. Laul A, Laul P, Merugumala V, Pathak R, Miglani U, Saxena P. Clinical Profiles of Dengue Infection during an Outbreak in Northern India. J Trop Med [Internet]. 2016 [cited 2017 Mar 5];2016:5917934. Available from: https:// www.ncbi.nlm.nih.gov/pmc/articles/PMC5153462/pdf/JTM2016-5917934.pdf 
19. Potts JA, Rothman AL. Clinical and laboratory features that distinguish dengue from other febrile illnesses in endemic populations. Trop Med Int Heal. 2008;13(11):1328-40.

20. Paz-Soldán VA, Morrison AC, Lopez JJC, Lenhart A, Scott TW, Elder JP, et al. Dengue Knowledge and Preventive Practices in lquitos, Peru. Am J Trop Med Hyg [Internet]. 2015 [cited 2017 Mar 6];93(6):1330-7. Available from: https://www.ncbi.nlm.nih.gov/pmc/articles/PMC4674254/ pdf/tropmed-93-1330.pdf

21. Alves AC, dal Fabbro AL, Passos ADC, Carneiro AFTM, Jorge TM, Martinez EZ Knowledge and practices related to dengue and its vector: a communitybased study from Southeast Brazil. Rev Soc Bras Med Trop. 2016:49(2)

22. Alyousefi TAA, Abdul-Ghani R, Mahdy MAK, Al-Eryani SMA, Al-Mekhlafi AM, Raja YA, et al. A household-based survey of knowledge, attitudes and practices towards dengue fever among local urban communities in Taiz Governorate, Yemen. BMC Infect Dis [Internet]. 2016 Oct 7 [cited 2017 mar 6];16(1):543. Available from: https://www.ncbi.n/m.nih.gov/pmc/articles/ PMC5054547/.

23. Sayavong C, Chompikul J, Wongsawass S, Rattanapan C. Knowledge, attitudes and preventive behaviors related to dengue vector breeding control measures among adults in communities of Vientiane, capital of the Lao PDR. J Infect Public Health [Internet]. 2015 [cited 2017 Mar 6];8:466-73. Available from: http://dx.doi.org/https://doi.org/10.1016/j.jiph.2015.03.005

24. Lugova H, Wallis S. Cross-Sectional Survey on the Dengue Knowledge, Attitudes and Preventive Practices Among Students and Staff of a Public University in Malaysia. J Community Health [Internet]. 2017 Apr 1 [cited 2017 Mar 5];42(2):413-20. Available from: http://link.springer.com/https://doi. org/10.1007/s10900-016-0270-y

25. Ministerio de la Protección Social, Instituto Nacional de Salud, Organización Paramericana de la Salud. GESTIÓN PARA LA VIGILANCIA ENTOMOLÓGICA Y CONTROL DE LA TRANSMISIÓN DE DENGUE [Internet]. [cited 2017 Nov 13]. Available from: http://www.paho.org/coL/index.php?option=com_ docman\&view=download\&category_slug=publicaciones-ops-omscolombia\&alias=1215-gestion-para-la-vigilancia-entomologica-y-control-dela-transmision-de-dengue\&ltemid $=688$

26. Heintze C, Garrido MV, Kroeger A. What do community-based dengue control programmes achieve? A systematic review of published evaluations. Trans R Soc Trop Med Hyg [Internet]. 2007 Apr 1 [cited 2017 Nov 13];101(4): 317-25. Available from: https://academic.oup.com/trstmh/article-lookup/doi/ , https://doi.org/10.1016/j.trstmh.2006.08.007

\section{Submit your next manuscript to BioMed Central and we will help you at every step:}

- We accept pre-submission inquiries

- Our selector tool helps you to find the most relevant journal

- We provide round the clock customer support

- Convenient online submission

- Thorough peer review

- Inclusion in PubMed and all major indexing services

- Maximum visibility for your research

Submit your manuscript at www.biomedcentral.com/submit 